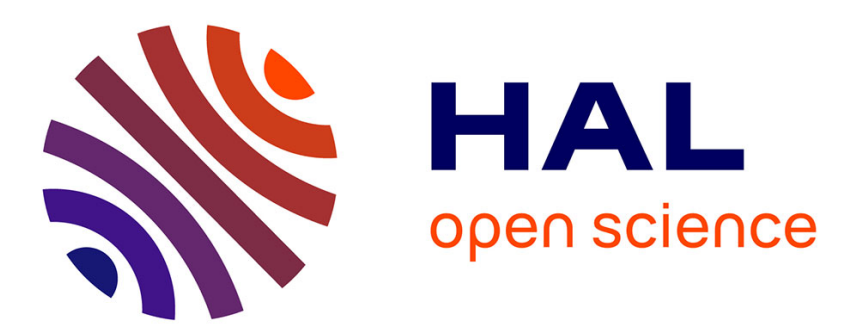

\title{
Simple method for resistance measurements on thin films and bulk of high Tc superconducting materials
}

\author{
G. Alzetta, Ennio Arimondo, R. Celli, F. Fuso
}

\section{To cite this version:}

G. Alzetta, Ennio Arimondo, R. Celli, F. Fuso. Simple method for resistance measurements on thin films and bulk of high Tc superconducting materials. Journal de Physique III, 1994, 4 (8), pp.14951501. 10.1051/jp3:1994216 . jpa-00249199

\section{HAL Id: jpa-00249199 https://hal.science/jpa-00249199}

Submitted on 1 Jan 1994

HAL is a multi-disciplinary open access archive for the deposit and dissemination of scientific research documents, whether they are published or not. The documents may come from teaching and research institutions in France or abroad, or from public or private research centers.
L'archive ouverte pluridisciplinaire HAL, est destinée au dépôt et à la diffusion de documents scientifiques de niveau recherche, publiés ou non, émanant des établissements d'enseignement et de recherche français ou étrangers, des laboratoires publics ou privés. 


\title{
Simple method for resistance measurements on thin films and bulk of high $T_{c}$ superconducting materials
}

\author{
G. Alzetta, E. Arimondo, R. M. Celli and F. Fuso \\ Dipartımento di Fisica, Università di Pısa, Piazza Torricellı 2, Pisa. Italy \\ (Recenced 10 March 1994, revised 3 May 1994, accepted 16 May 1994)
}

\begin{abstract}
Résumé. - On expose deux méthodes de mesure de la résıstıvité des supraconducteurs HTc en forme de couches minces déposées sur un substrat ou des céramiques frittées. Le dispositif de mesure, qui a été réalisé avec quatre contacts élastiques. permet d’obtenır des résultats reproductibles dans de très larges intervalles de température.

Abstract. - Two experimental techniques for measurıng resıstıvity behaviour of high $T_{\mathrm{t}}$ ceramic superconductors in bulk or thin films are described. Particular attention has been given to the development of a four point contact system, easy to use for relıable resistance measurements under repeated, wide thermal cycles.
\end{abstract}

\section{Introduction.}

The recent discovery of new high $T_{\iota}$ superconducting materials [1], has given a renovated emphasis to the studies of the resistive properties of superconducting devices and a world-wide interest in simple and reliable methods for the measurement of resistance in bulk materials and film depositions. A key for these measurements is to establish proper low-resistance contacts between the sample to be investigated and the resistance sensor apparatus. The contacts should maintain their properties over a large interval of temperatures, even in the presence of different thermal dilatations. Four contacts to the sample are required, as the method of four point contacts in the Smits configuration [2] is universally considered as the best and straightforward arrangement presently available for resistivity measurements. Several geometrical dispositions of the contacts are possible, to measure specifically the resistivity independently of the shape of the sample [3] or to detect the effects of the anisotropy of the sample itself on the resistivity measurement [4, 5]. The question of producing reliable contacts on superconducting high $T_{\mathrm{c}}$ materials is the most important and has been already examined by several authors. The most usual technique for realizing the required connections consists in soldering thin wires on top of evaporated contacts. References [6-8] report applications of this soldering technique in various arrangements. Alternatively, the applications of co-sintered contacts has been reported for some particular experimental configurations [9]. We have started an investigations of 
superconducting properties for bulk and thin films making use of different soldering configurations. It has been realized very soon that owing to different thermal dilatations these contacts are not able to withstand several temperature cycles, and, sometime, not a single one. In this work we present the way to solve, through an unsophisticated and inexpensive approach, the problems of the contacts between the superconducting sample and the temperature sensors. A technique based on elastic spring contacts has been developed and operated with very reliable results on a large variety of superconducting bulk materials and thin films.

\section{Electric contacts.}

The material to be employed for the electrical contacts on new high $T_{\mathrm{c}}$ superconductors must be chosen with proper attention. Semiconducting contacts as those made of aluminium, copper, indium and bismuth should be avoided because of large resistance of the contacts compared to the superconductor [9]. Either on bulk or film samples, the electric contacts obtained by fixing narrow copper wires on the sample by means of a conducting glue, mainly commercial silver pastes $[10,11]$, are a very common technique for resistivity measurement of superconductors. However, this technique requires high skill from the operator and moreover leads, very often in the case of repetitive thermal cycles, to a progressive disconnection of the silver glue contact from the superconductor surface. This disconnection is probably originated by the different thermal dilation coefficients of the two materials; the silver and the superconductor. The YBCO bulk resistance in the non superconducting state is often of the order of a few mOhms, much lower than that of the contacts and of wires that can be of the order of $10^{-1} \mathrm{Ohm}$. Therefore, as stressed in reference [12], any small change of the contacts and wires resistivity (due, e.g., to thermal variations) can be important for the measurement of the superconductor resistance.

\section{Elastic test probes and silver pads.}

From the point of view of simplicity for operator handling and for the exceptional reproducibility of the measurements, we have obtained very good results, both for bulk and thin films, by gently pressing elastic electro-mechanical tips on silver pads deposited against the sample surface (as presented in Fig. 1a). It is worthwhile to mention that the elastic tips, in stainless steel or brass metal, can be easily obtained at low cost and in small quantities, as spare parts for the most common watches. Moreover very good gold plated test probes for elastic contacts can be purchased from Ostby Barton Division of Everett Charles Technologies (i.e. model IP 27).

After some tests on different models, we have performed the resistivity measurements using elastic tips in chromium plated brass, because of the round form of the tip, which contacts more gently the film surface. Moreover those tips allow an easier tin soldering of the copper wires on the top side for providing the connections to the external measuring instruments, as shown in figure $1 \mathrm{~b}$. To obtain the four points array required for the Smith configuration [2], four probe tips have been introduced in a fiberglass strıp and blocked there using liquid perspex and solidified as depicted in figure $1 \mathrm{~b}$. All the array is pressed by two inox screws against the sample to be measured.

The best results for the pads deposited on the sample where the elastic tips are placed against, have been obtained by using a very small drop of silver glue (Demetron Leit silber 200). We have tested also contacts made of other metals, but we have encountered difficulties in the operations mainly because of the semiconducting nature of the contact itself [9]. Good fixing of the silver glue on the sample surface was obtained for drops with a typical 


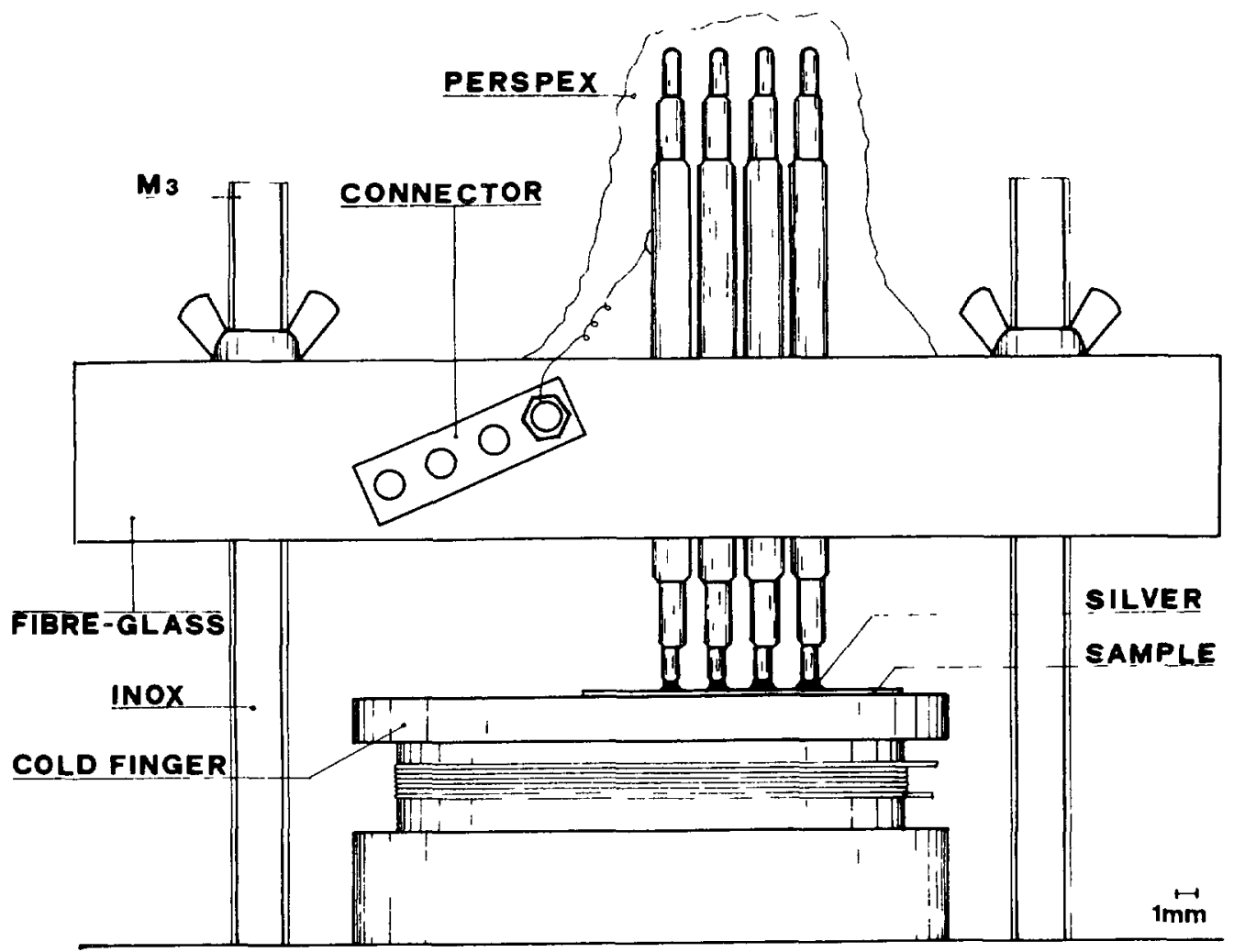

a)

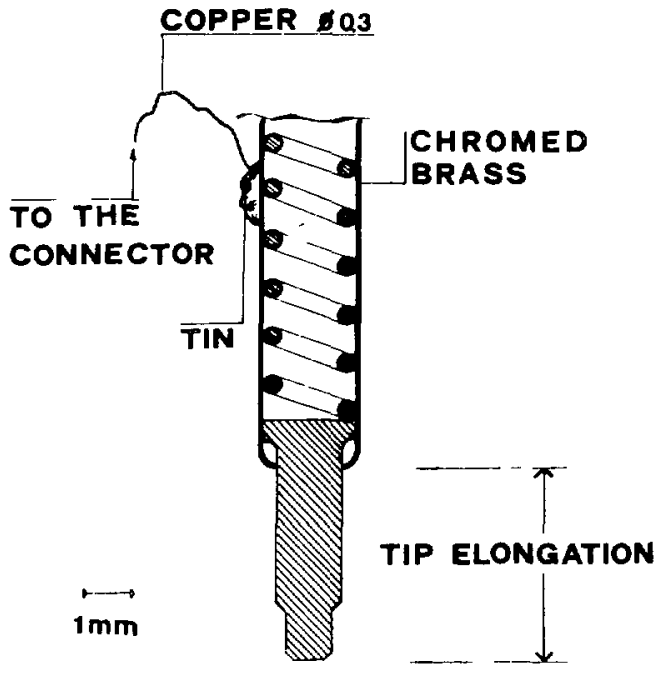

b)

Fig. 1. - Arrangement of a four-point probe for measuring HTSC resistance. a) Detail of the structure. For drawing clarity only one copper wire joining the contact probe to the connector has been sketched. b) A partial view of a section of the elastıc tıp probe. 
thickness of the order of $0.2 \mathrm{~mm}$ and a diameter less then one $\mathrm{mm}$. Occasionally, the sample surface was softly cleaned with acetone before glue deposition. After a drying period of a few hours, the elastic tips could be applied on the pads, and the whole electrical contacts were ready for the measurements. It should be stressed that no thermal annealing was required for the connections.

If measurements with accurate resistivity determinations are to be performed, a great care should be taken in measuring the distance between the four tips or in setting them at the correct geometry required by the theory for the resistivity determinations, as presented in references $[13,14]$.

By using the elastic probes and the silver pads we have been able to perform highly reproducible measurements; we report in the present work resistance measurements on YBCO thin films near the transition temperature. We have tested that all the result were perfectly reproducible when the sample temperature was swept up and down several times from room temperature to $20 \mathrm{~K}$. By the application of these contacts, we have been able to test quickly and easily, a large number of thin film samples in order to verify their quality, just after the deposition.

\section{Set-up for resistance measurement.}

In figure 2 the experimental layout for the d.c. measurements is reported, while in figure 3 the arrangement for a.c. measurements is shown. In both equipments the four point probe disposition of the electric contacts was used. The d.c. set-up has been employed both with bulks and films, while the a.c. measurements have been applied for bulk samples only. For modifying the sample temperature, a helium cryocooler (CTI Cryogenics model 22) was employed, driven by an IBM personal computer. Stabilization of the sample temperature was achieved making use of a high performance temperature controller (Lakeshore model 330). Great care was taken, in the whole mounting, to reduce the temperature drop between the

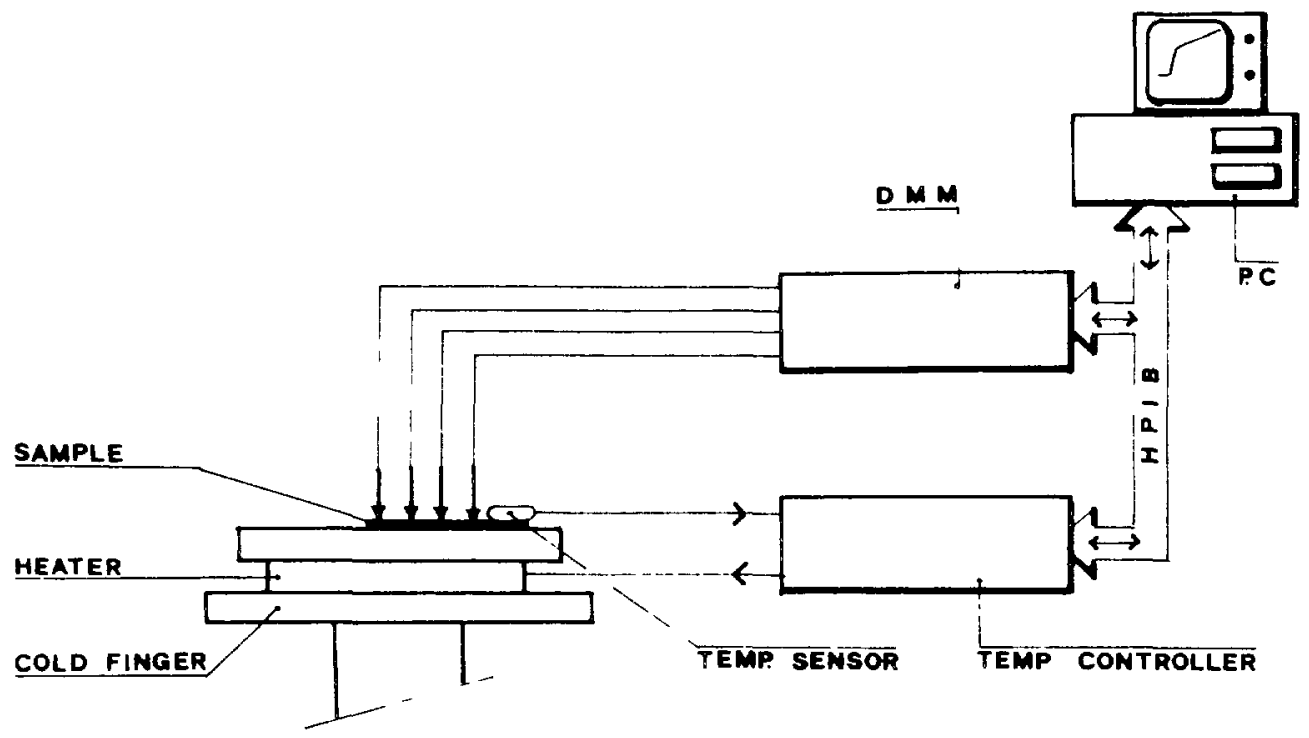

Fig. 2. - General schematic diagram of the electrical connections for temperature control for d.c. measurements on superconductor samples. 


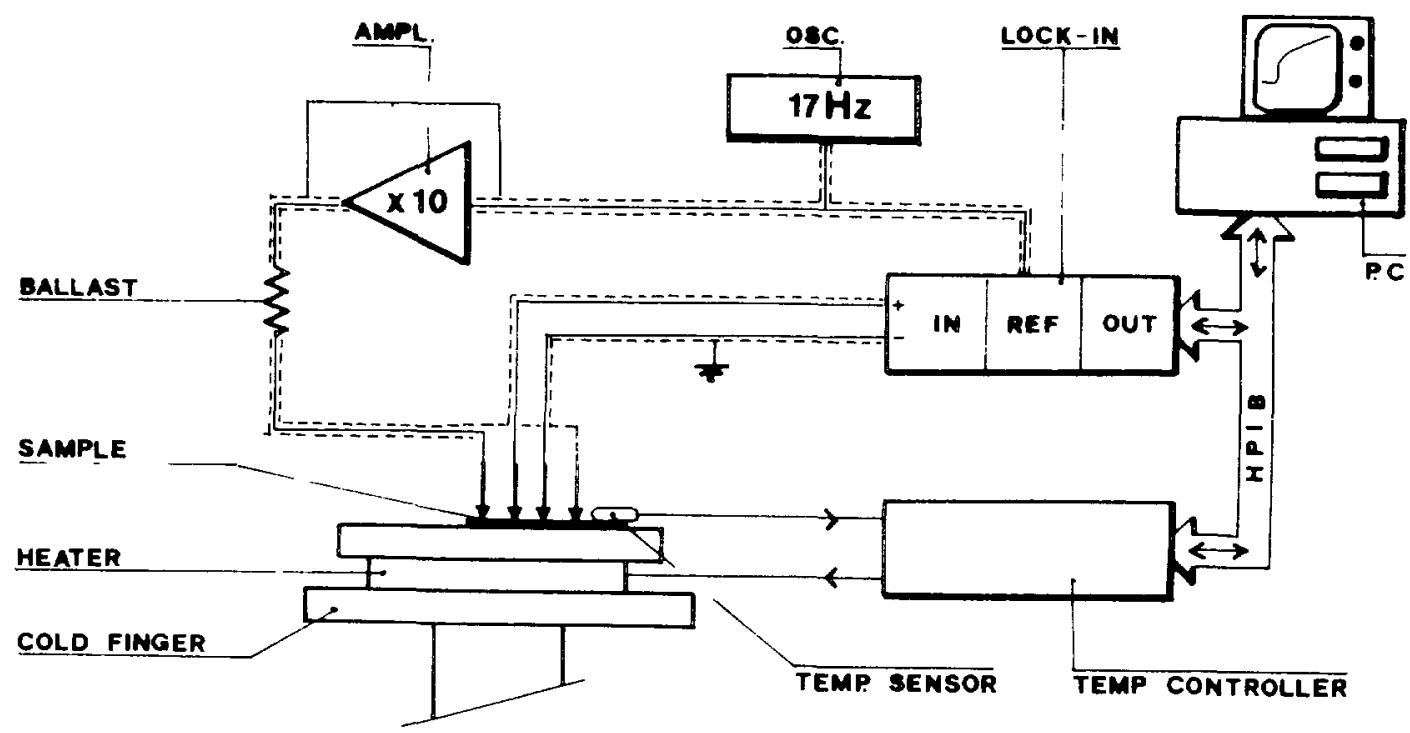

Fig. 3. - General schematic diagram of the lock-in detection system applied for very low resistance samples.

temperature sensor (Silicon diode Lakeshore TD-470) and the sample. Two separate temperature sensors, the first one used to drive the helium cryocooler and the second to measure the sample temperature, allowed to reach the required temperature accuracy and to control it. The temperature stability and accuracy was constantly better than $0.1 \mathrm{~K}$ over all the explored temperature range. During the cooling cycle, in both d.c. and a.c. cases, automatic reading of the temperature and resistance have been performed by a personal computer (IBM XT) via GPIB IEEE 488 bus. The d.c. resistances have been measured by an high precision digital multimeter (Fluke model $8840 \mathrm{~A}$ ). The a.c. measurements were performed by applying a small low-frequency modulation to the driving current and making use of a good performance lock-in (Stanford Research model 510). In the case of very low resistivity sample, good shielding of the connecting wires was required.

The d.c. measurements were applied to test the superconducting thin films deposited by laser ablation process. As described in reference [15], these films were produced by evaporation of bulk superconductors through focused excimer laser radiations and deposition on $\mathrm{MgO}$ (100) substrates. Films homogeneous over a $6 \mathrm{~mm}$ radius and typical thickness $\sim 5000 \AA$, were tested for superconductive properties. For these thin film measurements, an excitation current of $1 \mathrm{~mA}$ was used, corresponding to a current density inside the film around $1 \mathrm{~A} / \mathrm{mm}^{2}$. A typical result for the resistance of a laser deposited thin film is shown in figure 4a for a large temperature scan, and in figure $4 \mathrm{~b}$ for a restricted temperature interval near the phase transition temperature. Figure $4 \mathrm{~b}$ was obtained sweeping up and down the temperature several times: the high reproducibility of the measure may be noticed. On the same thin film sample with the same contact disposition, a.c. measurements have been also performed. Results similar to those of figure 4 were obtained. applying an excitation current much smaller than $1 \mathrm{~mA}$. Figure 5 reports the results of a.c. measurements on bulk superconductor samples. For these measurements an excitation current of the order of $0.1 \mathrm{~mA}$ was employed, corresponding to a density current for the bulk of a few $\mu \mathrm{A} / \mathrm{mm}^{2}$. The results of figure 5 were obtained using a modulation of the driving current at the frequency of $17 \mathrm{~Hz}$ : it was observed that in this 

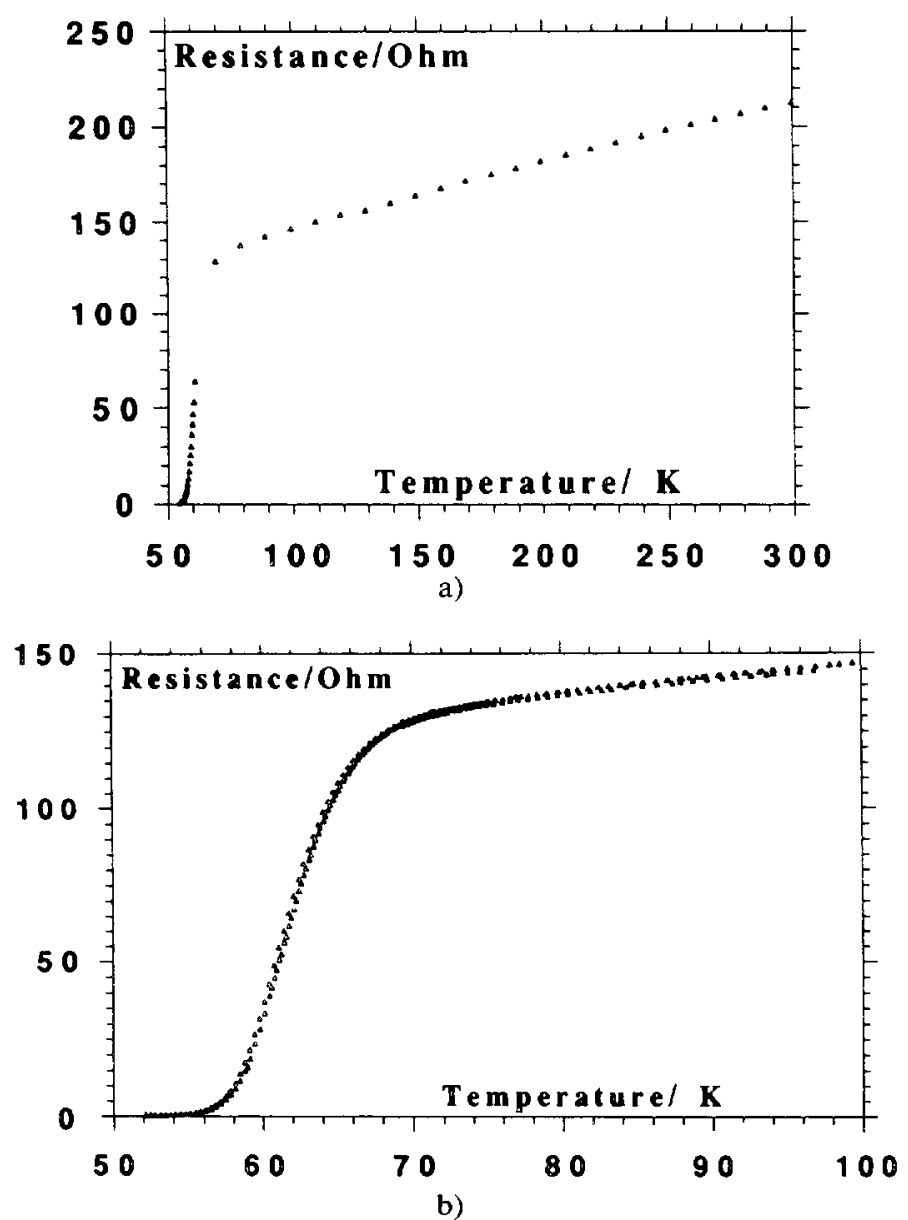

Fig. 4. - Resistance transition on YBCO film detected by d.c. measurement. In a) a large temperature scan is reported. In b) the resistance transition near $T_{\imath}$ : in this measurement many curves have been superposed, sweeping up and down the temperature.

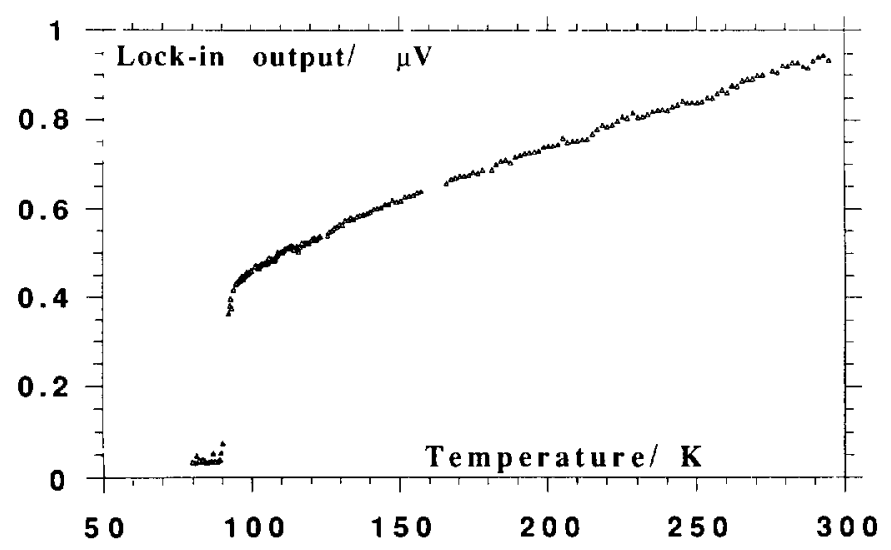

Fig. 5. - Resistance transition on YBCO bulk: a.c. measurement performed by the apparatus of figure 3 . 
conditions the maximum value for the $\mathrm{S} / \mathrm{N}$ ratio was achieved. In effect, it should be noticed that the presence of capacitive couplings between the probes did not allow us to use a modulation at a higher frequency. For a comparison of the sensitivity required for an a.c. measurements, we report out that a voltage of few microvolts at the central contact points was detected with an integration constant of $1 \mathrm{~s}$.

\section{Acknowledgments.}

The authors are indebted to Dr. I. Longo of I.F.A.M.-C.N.R. for important suggestions. This research has been performed at the Unità di Pisa del Consorzio Nazionale di Fisica della Materia within the activities of the Progetto Finalizzato Superconduttori del Consiglio Nazionale delle Ricerche. Italy.

\section{References}

[1] Lagues M., Xie X. M.. Tebbji H., Xu X. Z., Mairet V., Hatterer C., Beuran C. F.. Deville-Cavellin C.. Evidence suggesting superconductivity at $250 \mathrm{~K}$ in a sequentially deposited cuprate film, Science 262 (1993) 1850.

[2] Smits F. M., Measurement of sheet resistivitıes with the four point probe, Bell. Syst. Tech. J. 37 (1958) 711.

[3] Van der Pauw L. J., A method of measuring specific resıstivity and Hall effect of discs of arbitrary shape, Phlips Res. Repts 13 (1958) 1.

[4] Schnabel P.. Four-point method for measurıng the anisotropy of resistivity, Philips Res. Repts 19 (1964) 43.

[5] Price W. L. V.. Extension of van der Pauw s theorem for measuring specific resistivity in discs of arbitrary shape to anisotropic media, $J$ Phys D: Appl Phys. 5 (1972) 1127.

[6] Aponte J. M., Octavio M., Preparation and transport properties of high $T_{\mathrm{l}}$ superconducting thick film, J. Appl. Phys. 66 (1989) 1480.

[7] Agarwal M. K., Patel P. D.. Vijayan O., Electrical studies on (Mo/W)Se 2 sıngle crystal, Phys. Status Solude (A) 78 (1983) 103.

[8] Apte P. R., Kumar D., Pinto R., Sharon M., Gupta L. C., Vijayaraghavan R., A new contact conductance measurement technique for metal-HTSC film contact, IEEE Tians Appl. Supercond 2 (1992) 176.

[9] Subir Saha. Tripathı R. B., Das B. K., Properties of co-sıntered silver contacts to pure and silverdoped bulk YBCO superconductors, Supercond Sc, Technol. 5 (1992) 703.

[10] Pfalzgraf B. W., Spreckels H., Muischer H., Four point dc-resistance measurement apparatus for anisotropic crystals, Rel. Scl. Instrum. 57 (1985) 941.

[11] Strbik V., Boon W., Chromık S.. Bruynsereade Y., Benacka S., Resistive transition of YBCO thin film in an high magnetic field, Supercond. Sci Technol 3 (1990) 454.

[12] Brown G. C., Rasure J. O., Simple demonstration of superconductivity in YBCO, Am. J Phys. 57 (1989) 1142.

113] Yamashita M., Resistivity correction factor for the four-probe method, J. Phys. E : Scı Instrum. 20 (1987) 1454.

[14] Koon D. W., Effect of contact size and placement. and of resistive inhomogeneities on van der Pauw measurements, Rev Scl. Instrum. 60 (1989) 271.

[15] Masciarelli G., Fuso F., Iembo A., Allegrini M., Arimondo E., High $T_{c}$ Superconductor Thın Films, L. Correra Ed. (Elsevier, Amsterdam, 1992) p. 819. 